\title{
Die aanwending van 'n eenvoudige grondwaterbalans om droogte in natuurlike veld te karakteriseer
}

Ontvang 19 Junie 1990; aanvaar 31 Janwarie 1991

\author{
ABSTRACT \\ Application of a simple soil water balance to characterise drought in natural veld
}

The characterisation of drought is something which has caused much debate and investigation and is even in the nineties still a thorny problem. This article describes a method whereby drought in natural veld is characterised by using a soil water balance to build a "climatology" of soil water content. The real time situation is then compared to the "soil water climate" and described in terms of probabilities. A sensitivity analysis showed that it will be necessary to know the actual available soil moisture capacity of the soil to a high degree of accuracy, especially in shallow soils, but in deeper soils it should be known to the nearest $50 \mathrm{~mm}$, before this proposed method can yield acceptable results.

\section{INLEIDING}

Droogte is een van daardie konsepte waarvoor die gemiddelde mens 'n intuïtiewe aanvoeling het, maar wat nogtans moeilik is om te kwantifiseer. In Suid-Afrika is die droogte van die 1930's wat met die depressiejare saamgeval het, vir dekades beskou as die "Groot Droogte". Hierdie droogte is in baie gevalle oortref deur die droogte wat in die vroeë tot middel tagtigerjare geheers het. Daar is heelwat polemiek oor watter van dié twee droogtes, vyf dekades van mekaar verwyder, nou die ergste was. Dit wil dikwels voorkom of dit soos skoonheid 'n kwessie van smaak is van watter die ergste (of mooiste) is. Tannehill' het beweer dat daar geen goeie definisie van droogte bestaan nie en dat ons skaars 'n droogte ken as ons dit sien. Wilhite \& Glant $\mathrm{z}^{2}$ het gereken dat ons moet konsentreer op operasionele definisies van droogte, wat almal die uitgangspunt het dat droogte veroorsaak word deur 'n gebrek aan neerslag en dit dan op 'n spesifieke manier uitdruk en verder ander parameters byvoeg soos evapotranspirasie, temperatuur, wind en andere soos wat in die bepaalde geval nodig mag wees.

Sedert 1982 word die Palmer-metode ${ }^{3}$ in Suid-Afrika gebruik om droogte te kwantifiseer. Dit is so ver moontlik verfyn wat die berekening en interpolasie betref, dog dit voldoen nie aan die vereistes van die beleidmakers ${ }^{4}$ nie. Daarom is daar besluit om voort te gaan met die daarstelling van gewasspesifieke indekse. In 'n vorige artikel' is 'n metode beskryf om droogte van mielies te kwantifiseer deur gebruik te maak van 'n deterministiese groeimodel. In hierdie artikel word 'n heel ander benadering vir natuurlike veld beskryf na aanleiding van die FoDewsmodel $^{6}$ wat in Kanada gebruik word.

\section{LITERATUUROORSIG}

Aangesien die Palmer-metode ${ }^{3}$ nie vir die beleidmakers aanvaarbaar was nie en Booysen ${ }^{7}$ ook gevind het dat dit nie 'n goeie aanduiding van die groei van klimaksgrasse by Glen was nie, is hierdie metode as nie geskik beskou om verder te probeer verfyn vir die daarstelling van 'n droogte-indeks vir natuurlike veld in Suid-Afrika nie. 'n Alternatief is die FoDews-model ${ }^{6}$ wat in die prairieprovinsies van Kanada gebruik word. Daar is gevind dat hierdie model nie in Suid-Afrika as 'n voorspelling van droogtetoestande oor drie maande gebruik kan word nie, ${ }^{5}$ omdat die grondwater in die vroeë somer in Kanada hoofsaaklik van gesmelte sneeu afkomstig is, wat nie die geval in Suid-Afrika is nie. Daar is egter geen rede waarom dit nie getoets sou word om intydse evaluasies van die droogtetoestand te maak nie. Hierdie model bereken grondwaterinhoud deur van 'n grondwaterbalansmodel gebruik te maak. Hierdie grondwaterwaardes kan dan bereken word vir 'n hele aantal jare, sodat daar dan 'n "klimatologie" van hierdie waardes (analoog aan die klimatologie van reënval, wind of temperatuur) opgebou word. Dan kan die oombliklike (intydse) waardes gedurende die seisoen vergelyk word met die geskiedkundige "klimatologie" en dan kan bepaal word of dit droër of natter as normaal is. Indien die "grond waterklimaat" vir 'n genoegsame aantal jare bereken is, kan die intydse situasie dan statisties uitgedruk word in terme van waarskynlikhede of herhalingsperiodes soos 'n een uit tien jaar droogte.

\section{MATERIAAL EN METODES}

As 'n beginpunt is 'n eenvoudige grondwaterbalansmodel ontwikkel vir natuurlike veld, gebaseer op die evapotranspirasiestudie van Opperman" en soortgelyke modelle vir koring ${ }^{10}$ en mielies." Hierdie model gebruik daaglikse Klas A-panverdamping en reënval as insette en die primêre afvoer is die daaglikse berekende grondwaterinhoud (GWI). Hierdie parameter kan dan maklik omgeskakel word na die persentasie beskikbare grondwater (\%BGW), oftewel die werklike grondwater uitgedruk as 'n persentasie van die grondwaterhouvermoë wat vergelyking tussen verskillende grondsoorte en plekke meer sinvol maak. As 'n beginpunt is die "klimatologie" van hierdie parameter vir 'n paar plekke met lang weerrekords geëvalueer. Die model is met die rekenaar bedryf en 'n waarskynlikheidsanalise is op 
TABEL 1

Mediane, eerste en derde kwartiele van \% beskikbare grond water (\% BGW) vir'n natuurlike veld by 'n paar geselekteerde weerstasies

\begin{tabular}{|c|c|c|c|c|c|c|c|c|c|}
\hline Stasie & \multicolumn{3}{|c|}{ Potchefstroom (110) } & \multicolumn{3}{|c|}{ Cedara (150) } & \multicolumn{3}{|c|}{ Cedara $(100)^{*}$} \\
\hline Maand & QI & Mediaan & Q3 & Q1 & Mediaan & Q3 & Ql & Mediaan & Q3 \\
\hline Sept. & $-5,3$ & -0.1 & 19.2 & 25.9 & 46,0 & 69.9 & 29.5 & 77.8 & 92,4 \\
\hline Okt. & 9,8 & 21,5 & 49,0 & 57,4 & 88,4 & 99,7 & 76,0 & 98,6 & 100,0 \\
\hline Nov. & 27,6 & 61,2 & 85,9 & 95,7 & 98,7 & 99,5 & 96,9 & 98,4 & 100,0 \\
\hline Des. & 31,5 & 62,4 & 84,9 & 94,7 & 97,6 & 100,0 & 92,2 & 96,5 & 99.9 \\
\hline Jan. & 14,8 & 52,4 & 83.6 & 83,3 & 93,9 & 99,6 & 75,0 & 90,9 & 99,4 \\
\hline Feb. & 8,1 & 33,6 & 67,1 & 70,8 & 86,3 & 95,1 & 56,2 & 79,5 & 85,1 \\
\hline Maart & $-3,5$ & 3.5 & 52,3 & 56,1 & 74,0 & 90,1 & 37,2 & 61,0 & 85,1 \\
\hline April & -6.2 & $-2,6$ & 13,6 & 18,8 & 51,8 & 72,3 & $-0,5$ & 30.9 & 58.5 \\
\hline Mei & $-10,3$ & -5.0 & $-2,0$ & $-1,2$ & 27,6 & 44,7 & $-3,5$ & -0.6 & 21,5 \\
\hline Junie & $-14,0$ & $-7,3$ & $-2,6$ & $-1,5$ & 8,5 & 27,2 & $-4,6$ & $-1,8$ & 9,2 \\
\hline Julie & $-15,1$ & -6.7 & $-0,9$ & $-0,9$ & 7,6 & 29,3 & $-3,2$ & $-0,5$ & 14,3 \\
\hline Aug. & -10.8 & -3.6 & -0.4 & 3,2 & 18,8 & 44,4 & 0.2 & 16,6 & 52,2 \\
\hline Stasie & \multicolumn{3}{|c|}{ Grootfontein (100) } & \multicolumn{3}{|c|}{ Elsenburg (125) } & \multicolumn{3}{|c|}{ Langgewens (100) } \\
\hline Maand & Q1 & Mediaan & Q3 & Q1 & Mediaan & Q3 & Q1 & Mediaan & Q3 \\
\hline Sept. & $-2,3$ & 7.5 & 26,5 & 98,0 & 99,5 & 99.9 & 84,6 & 97,8 & 99.7 \\
\hline Okt. & $-0,6$ & 5,7 & 33,4 & 90,7 & 97,9 & 99,4 & 70,4 & 85,3 & 93,8 \\
\hline Nov. & $-1,9$ & 4,9 & 47,3 & 65,3 & 85,9 & 93.1 & 20.7 & 46.8 & 78.3 \\
\hline Des. & $-5,0$ & -1.7 & 23,6 & 11,7 & 42,4 & 69,2 & $-6,3$ & $-1,5$ & 25,3 \\
\hline Jan. & $-4,9$ & $-0,5$ & 19,3 & $-5,5$ & $-1,6$ & 44,8 & -15.5 & $-8,6$ & $-2,8$ \\
\hline Feb. & $-6,9$ & -1.2 & 27,2 & $-10,5$ & $-2,9$ & 2,3 & $-23,8$ & $-12,5$ & $-2,8$ \\
\hline Maart & $-6,7$ & $-0,8$ & 13,3 & $-11,1$ & $-3,2$ & $-1,2$ & $-24,4$ & $-17,9$ & $-4,7$ \\
\hline April & $-9,9$ & $-4,7$ & 0,8 & $-4,9$ & $-1,1$ & 17,5 & $-24,1$ & $-4,5$ & 1,3 \\
\hline Mei & $-13,2$ & $-7,3$ & -2.9 & 8,6 & 36,6 & 63,5 & $-2,7$ & 0,6 & 28,2 \\
\hline Junie & $-15,9$ & $-6,8$ & $-2,3$ & 48,0 & 73,6 & 96,6 & 8,9 & 25,4 & 71,4 \\
\hline Julie & $-12,9$ & -3.3 & 0,0 & 87,6 & 97,1 & 99.1 & 36,2 & 53,9 & 95.9 \\
\hline Aug. & $-10,2$ & $-1,0$ & 10,4 & 98,9 & 99.7 & 100,0 & 74,1 & 97,6 & 99,7 \\
\hline
\end{tabular}

*Die syfers in hakies is die totale beskikbare grondwaterhouvermoë in $\mathrm{mm}$

die berekende \% BGW-waardes aan die einde van elke maand gedoen. In tabel 1 word die kwartielwaardes aangegee van \% BGW vir 'n paar plekke met uiteenlopende reënvalkarakteristieke, van droog tot nat en van somer- tot winterreënvalgebiede. Die eerste en derde kwartiele verteenwoordig die onderste en boonste grense van die gebied waarbinne die grondvoginhoud 50 persent van die tyd behoort te wees en dus as redelik normaal beskryf kan word. In een jaar uit vier sal dit óf bokant die derde kwartiel (dus bonormaal nat) óf onder die eerste kwartiel (dus bonormaal droog) lê.

Hierdie metode lyk op die oog af belowend, aangesien dit maklik is om vir enige plek eers die "grondwaterklimatologie" te bereken en daarna intyds die model aan die einde van elke maand te bedryf en dan die berekende $\%$ BGW te vergelyk met die historiese rekord en dit as 'n waarskynlikheid of herhalingsperiode uit te druk wat vir die beleidmakers 'n sinvolle idee kan gee van hoe droog of hoe nat dit is. Dit is egter nodig om vas te stel hoe goed hierdie metode in die praktyk sal vaar. Die grootste praktiese probleem is die feit dat die beskikbare grondopnames nie in soveel detail gedoen is dat die werklike grondwaterhouvermoë van die gronde in situ noukeurig bekend is nie. Dit is dus nodig om vas te stel tot watter mate van noukeurigheid hierdie laasgenoemde parameter bekend moet wees om vir praktiese doeleindes van droogte-
TABEL 2

Weerstasies en die jare uit die historiese rekord wat gebruik is, en die gemiddelde en mediaan jaarlikse reënval vir dié jare

\begin{tabular}{|l|c|c|c|}
\hline Weerstasie & $\begin{array}{c}\text { Jare uit } \\
\text { rekord } \\
\text { gebruik }\end{array}$ & \multicolumn{2}{|c|}{$\begin{array}{c}\text { Jaarlikse reënval } \\
\text { (mm) } \\
\text { Gemiddelde }\end{array}$} \\
\hline Grootfontein, Middelburg & $1916-84$ & 360,3 & 283,9 \\
Langgewens, Swartland & $1931-84$ & 393,0 & 337,0 \\
Mara, Louis Trichardt & $1950-70$ & 395,4 & 336,6 \\
Armoedsvlakte, Vryburg & $1934-84$ & 447,1 & 378,6 \\
Glen, Bloemfontein & $1922-84$ & 539,1 & 457,0 \\
Potchefstroom & $1914-84$ & 626,7 & 548,4 \\
Nooitgedacht, Ermelo & $1942-84$ & 728,4 & 666,5 \\
Döhne, Stutterheim & $1939-84$ & 744,3 & 639.0 \\
Bien Donné, Paarl & $1941-83$ & 810,3 & 691,5 \\
Cedara, Howick & $1950-84$ & 872,0 & 769,0 \\
\hline
\end{tabular}

evaluering nog nuttig te kan wees. Om die effek van grondwaterhouvermoë met hierdie metode vas te stel, is die grondwatermodel laat loop met weergegewens van 10 weerstasies met langtermynrekords in uiteenlopende klimaatgebiede (tabel 2). Die berekende \%BGW vir die einde van elke maand, asook die totale reënval $(R)$ van elke maand is in 'n rekenaarlêer geberg. 'n Program wat van Dyer ${ }^{6}$ in Kanada verkry is, is gebruik om die volgende waarskynlikheidswaardes vir sowel $\mathrm{R}$ as $\% \mathrm{BGW}$ te bereken:

$$
\begin{array}{ll}
10 \% & \text {-een jaar uit tien } \\
25 \% & \text {-een jaar uit vier } \\
33,3 \% & \text {-een jaar uit drie } \\
50 \% & \text {-een jaar uit twee } \\
66,7 \% & \text { - twee jare uit drie } \\
75 \% & \text { - drie jare uit vier }
\end{array}
$$

Hierdie program het terselfdertyd vir elke maand in die historiese rekord sowel $\mathrm{R}$ as \% BGW in een van die bogemelde ses klasse geklassifiseer. Die program is vir elke weerstasie bedryf vir vier waardes van totale grondwaterhouvermoë (GWH), naamlik 50, 100, 150 en 200 $\mathrm{mm}$. Daar was dus vir elke maand van die historiese rekord behalwe die waardes van $\mathrm{R}$, die waardes van \% BGW vir die vier veronderstelde waardes van GWH, asook die klassifikasie van $\mathrm{R}$ en die \%BGW in een van die ses klasse hier bo aangedui. Dus kon vasgestel word of droogte vir 'n spesifieke maand - soos uitgedruk in herhalingstydperke vir die parameters reënval $(R)$ en persentasie beskikbare grondwater (\% BGW) - vir elk van vier grondsoorte met grondwaterhouvermoëns wat strek van 50 tot $200 \mathrm{~mm}$, ooreenstem al dan nie. Die historiese rekord is nagegaan en die aantal kere wat die droogteklassifikasie vir byvoorbeeld $\mathrm{R}$ ooreengestem het met dié vir \% BGW50 (\% BGW as GWH $50 \mathrm{~mm}$ is), is dit uitgedruk as 'n persentasie van die totale aantal gevalle in die historiese rekord waarvoor die parameters bereken is.

\section{RESULTATE EN BESPREKING}

Soos reeds vermeld word die weerstasies waarvoor die analise gedoen is, in tabel 2 aangedui. Hierdie weerstasies verteenwoordig 'n wye reeks van klimaatstoestande in Suid- 
TABEL 3

Persentasieooreenkoms tussen droogteklassifikasies met reënval $(R)$ as parameter en met persentasie beskikbare grondwater (\% BGW) vir vier verskillende grondwaterhouvermoëns as parameter

\begin{tabular}{|c|c|c|}
\hline Weerstasie & Parameters vergelyk & $\begin{array}{c}\text { Persentasie } \\
\text { ooreenkoms }\end{array}$ \\
\hline Grootfontein & 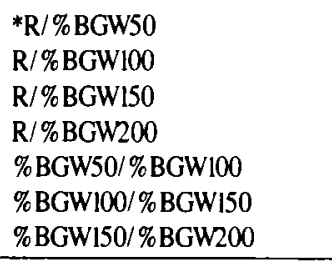 & $\begin{array}{l}34,9 \\
34,7 \\
34,6 \\
34,3 \\
75,0 \\
85,4 \\
87,5\end{array}$ \\
\hline Langgewens & $\begin{array}{l}\text { R/\% BGW50 } \\
\text { R/\%BGW100 } \\
\text { R/\%BGW150 } \\
\text { R/\%BGW200 } \\
\% \text { BGW50/\% BGW100 } \\
\% \text { BGW100/\% BGW150 } \\
\% \text { BGW150/\%BGW200 }\end{array}$ & $\begin{array}{l}31,8 \\
32,5 \\
33,3 \\
30,2 \\
59,3 \\
56,6 \\
64,2 \\
\end{array}$ \\
\hline Mara & $\begin{array}{l}\text { R/\% BGW50 } \\
\text { R/\%BGW100 } \\
\text { R/\%BGW150 } \\
\text { R/\%BGW200 } \\
\% \text { BGW50/\%BGW100 } \\
\% \text { BGW100/\%BGW150 } \\
\text { \%BGW150/\%BGW200 }\end{array}$ & $\begin{array}{l}37,1 \\
39,6 \\
37,9 \\
33,3 \\
67,1 \\
74,2 \\
84,6 \\
\end{array}$ \\
\hline Armoedsvlakte & $\begin{array}{l}\text { R/\%BGW50 } \\
\text { R/\%BGW100 } \\
\text { R/\%BGW150 } \\
\text { R/\%BGW200 } \\
\% \text { BGW50/\%BGW100 } \\
\% \text { BGW100/\%BGW150 } \\
\% \text { BGWI50/\%BGW200 }\end{array}$ & $\begin{array}{l}34,2 \\
36,7 \\
36,8 \\
36,8 \\
67,8 \\
85,0 \\
93,5 \\
\end{array}$ \\
\hline Glen & $\begin{array}{l}\text { R/\%BGW50 } \\
\text { R/\%BGW100 } \\
\text { R/\%BGW150 } \\
\text { R/\%BGW200 } \\
\% \text { BGW50/\% BGW100 } \\
\% \text { BGW100/\%BGW150 } \\
\% \text { BGW150/\%BGW200 }\end{array}$ & $\begin{array}{l}21,6 \\
22,7 \\
22,3 \\
21,8 \\
78,4 \\
84,0 \\
84,4\end{array}$ \\
\hline
\end{tabular}

Afrika, wat ook die spektrum van winter- tot somerreënvaltoestande insluit. In tabel 3 word die ooreenstemmings van die klassifikasie van droogte gegee deur van reënval (R) en die \% BGW vir grondsoorte met voghouvermoëns van 50 tot $200 \mathrm{~mm}$ gebruik te mak.

Dit is duidelik dat daar nie juis 'n ooreenkoms bestaan tussen die klassifikasie met reënval as weerkundige parameter en enige van die grondwaterparameters nie. Dit wil sê waar die maandelikse reënval miskien op 'n droë maand in die kategorie een jaar uit tien dui as daar net na die reënval gekyk word, sal selfs vir vlak grond met slegs $50 \mathrm{~mm}$ grondwaterhouvermoë dit slegs in ongeveer $30 \%$ van die gevalle ook dui op 'n een uit tien jaar droogte. Dit is egter duidelik dat waar die grondwaterhouvermoë nie meer as $50 \mathrm{~mm}$ verskil nie, die ooreenkoms heelwat hoër is en in sommige gevalle bokant 90 persent. Dit is ook duidelik dat hoe groter die grondwaterhouvermoë, hoe minder word die klassifikasie versteur deur die feit dai die presiese grondwaterhouvermoë nie bekend is nie, aange-

\begin{tabular}{|c|c|c|}
\hline Potchefstroom & $\begin{array}{l}\text { *R/\%BGW50 } \\
\text { R/\%BGVW00 } \\
\text { R/\%BGVW50 } \\
\text { R/\%BGVW00 } \\
\% \text { BGW50/\%BGWl00 } \\
\% \text { BGW100/\%BGWI50 } \\
\% \text { BGW150/\%BGW200 }\end{array}$ & $\begin{array}{l}37,5 \\
37,1 \\
33,9 \\
33,7 \\
52,4 \\
64,2 \\
80,1\end{array}$ \\
\hline Nooitgedacht & $\begin{array}{l}\text { R/\%BGW50 } \\
\text { R/\%BGWI00 } \\
\text { R/\%BGW150 } \\
\text { R/\%BGW200 } \\
\% \text { BGW50/\%BGW100 } \\
\% \text { BGW100/\%BGW150 } \\
\% \text { BGW150/\%BGW200 }\end{array}$ & $\begin{array}{l}33,3 \\
34,3 \\
34,5 \\
29,2 \\
60,1 \\
58,5 \\
56,9\end{array}$ \\
\hline Döhne & $\begin{array}{l}\text { R/\%BGW50 } \\
\text { R/\%BGW100 } \\
\text { R/\%BGW150 } \\
\text { R/\%BGW200 } \\
\% \text { BGW50/\%BGW100 } \\
\% \text { BGW100/\%BGW150 } \\
\% \text { BGW150/\%BGW200 }\end{array}$ & $\begin{array}{l}29,8 \\
31,3 \\
28,7 \\
28,7 \\
59,1 \\
85,7 \\
93,5\end{array}$ \\
\hline Dien Donné & $\begin{array}{l}\mathrm{R} / \% \mathrm{BGW} 50 \\
\mathrm{R} / \% \mathrm{BGW} 100 \\
\mathrm{R} / \% \mathrm{BGW} 150 \\
\mathrm{R} / \% \mathrm{BGW} 200 \\
\% \mathrm{BGW} 50 / \% \mathrm{BGW} 100 \\
\% \mathrm{BGW} 100 / \% \mathrm{BGW} 150 \\
\% \mathrm{BGW} 150 / \% \mathrm{BGW} 200\end{array}$ & $\begin{array}{l}29,5 \\
28,5 \\
30,0 \\
27,5 \\
68,4 \\
69,0 \\
77,1\end{array}$ \\
\hline Cedara & $\begin{array}{l}\text { R/\%BGW50 } \\
\text { R/\%BGW100 } \\
\text { R/\%BGW150 } \\
\text { R/\%BGW200 } \\
\% \text { BGW50/\%BGW100 } \\
\% \text { BGW100/\%BGW150 } \\
\text { \%BGWI50/\%BGW200 }\end{array}$ & $\begin{array}{l}34,3 \\
30,6 \\
27,9 \\
28,4 \\
55,6 \\
65,9 \\
80,9\end{array}$ \\
\hline
\end{tabular}

$* \mathrm{R}=$ totale maandelikse reënval

$\%$ BGW50 $=\%$ BGW vir $50 \mathrm{~mm}$ grondwaterhouvermoë

$\% \mathrm{BGW} 100=\% \mathrm{BGW}$ vir $100 \mathrm{~mm}$ grondwaterhouvermoë

$\%$ BGWl50 $=\%$ BGW vir $150 \mathrm{~mm}$ grondwaterhouvermoë

$\%$ BGW200 $=$ \% BGW vir $200 \mathrm{~mm}$ grondwaterhouvermoë

sien ' $\mathrm{n}$ verskil van $50 \mathrm{~mm}$ in grondwaterhouvermoë ' $\mathrm{n}$ meer as 80 persent ooreenstemming in droogteklassifikasie veroorsaak, weens die feit dat die effek van reënval dan gebuffer word. Uitsonderings op die reël is Langgewens in die Swartland en Nooitgedacht naby Ermelo, waar die ooreenkomste in die orde van 60 persent is.

\section{GEVOLGTREKKING}

Die resultate dui daarop dat enige droogteklassifikasie wat slegs van reënval gebruik maak, met groot omsigtigheid hanteer moet word, aangesien daar min ooreenkoms bestaan tussen so ' $n$ klassifikasie en een wat van grondwaterinhoud gebruik maak. Dit is dus uiters gevaarlik om stellings te maak oor die graad van droogte wat slegs op reënval gebaseer is, aangesien dit deur die waterhouvermoë van die grond is wat reënval die groei en produksie van plante beïnvloed. Dit wil voorkom of ' $n$ skema wat van die "grondwaterklimatologie" gebruik maak, wel waarde kan hê indien die grondwaterhouvermoë van die grondsoorte waarop 
die natuurlike veld voorkom, tot 'n hoë mate van noukeurigheid bekend is - liefs binne $50 \mathrm{~mm}$ vir grondsoorte met 'n waterhouvermoë van meer as $50 \mathrm{~mm}$, en heelwaarskynlik nog noukeuriger vir vlakker grondsoorte. (Met die gegewens tot ons beskikking is dit nie moontlik om 'n presiese syfer hieraan te koppel nie.) Hierdie werk moet as voorlopig beskou word; daar sal verdere werk nodig wees om hierdie metode vir die praktyk af te rond.

\section{A.L. DU PISANI}

S.A. Weerburo, Privaat sak X97, Pretoria 0001

\section{LITERATUURVERWYSINGS}

1. Tannehill, I.R. (1947). Drought, Its causes and effects (Princeton University Press, Princeton, New Jersey).
2. Wilhite, D.A. \& Glantz, M.H. (1987), Understanding the Drought Phenomenon: The Role of Definitions. In Planning for Drought, Wilhite, D.A. \& Easterling, W.E. eds. (Westview, Boulder and London) p. 11-27.

3. Palmer, W.C. (1965). Meteorological Drought, Res. Paper No. 45, U.S. Department of Commerce, Weather Bureau.

4. Bruwer, J.J. (1989). Drought Policy in the Republic of South Africa Paper presented to SARCCUS workshop on Drought, 27 June 1989.

5. Du Pisani, A.L. (1987). The CERES-MAIZE model as a potential tool for drought assessment in South Africa, Water SA, 13, 159-164.

6. Dyer, J.A., Stewart, R.B. \& Muma, R.W. (1982). A weather based early warning system for spring forage in Western Canada, Can. Farm Econ. , 17(4), 9-16

7. Booysen, J. (1983). Twee metodes vir die kwantitatiewe simulering van groeitoestande van klimaksgras. UOVS, Bloemfontein, Ongepub. M.Sc.-verhandeling.

8. Dyer, J.A. \& De Jager, J.M. (1984). The predictability of Summer Drought Conditions in South African Grassland. Water Intl. , 11, 78-87.

9. Opperman, D.P.J. (1975). Vog- en ontblaringstudies op meerjarige grasse in die Sentrale Oranje-Vrystaat. Ongepub. D.Sc.-verhandeling.

10. Du Pisani, A.L. (1976). The use of a simple computer model to calculate the moisture supply potential for wheat for certain inland areas of South Africa, Crop Prod., 5, 31-35.

11. Du Pisani, A.L. (1978). The application of a moisture budget in determining maize yield potential, Dept. ATS, Tech. Comm. No. 165. p. $21-215$. 